\title{
Erratum to: Mindfulness in Action: The Emergence of Distinctive Thought and Behavior
}

\author{
Robin R. Vallacher, Matthew S. Jarman and Steven S. Parkin
}

\section{Erratum to:}

Chapter "Mindfulness in Action: The Emergence of Distinctive Thought and Behavior" in: S.M. Fatemi (ed.), Critical Mindfulness, DOI 10.1007/978-3-319-30782-4_8

The original version of the book was inadvertently published without the following updated corrections:

In Chapter 8, the sequence of author names should be corrected to "Robin R. Vallacher, Mathew S. Jarman, Steven S. Parkin" and biographies of the authors "Matthew S. Jarman, Steven S. Parkin" should be added.

The erratum chapter and the book have been updated with the changes.

The updated original online version for this chapter can be found at http://dx.doi.org/10.1007/ 978-3-319-30782-4_8 